\title{
Translation as Strategic Foreignization: A Study of the Politics of Translation in Mother Forest: An Unfinished Autobiography
}

\author{
Dr. Liju Jacob Kuriakose \\ Assistant Professor, Department of Language and Literature at Alliance University, Bangalore. \\ Email:liju.kuriakose@alliance.edu.in. https://orcid.org/0000-0001-7726-0554
}

\begin{abstract}
The study draws upon Lawrence Venuti's concept of foreignization as a strategic tool employed in the translation of CK Janu's Mother Forest: An Unfinished Autobiography. The translation works to mould an ethnic autobiography and represent a subaltern subject through explicit signifiers of subalternity, masqueraded as an attempt to "retain the flavour of Janu's intonation and the sing-song nature of her speech in translation". As a mode of representation, this study identifies the text as catering to a transnational publishing industry and the global academic marketplace, transforming the cultural value of an ethnic subaltern text into what Graham Huggan describes as "tawdry ethnic goods" in the late capitalist supermarket.
\end{abstract}

Keywords: Translation, Strategic Foreignization, Autobiography, Ethnic Goods

\section{Introduction}

"By whom and, especially, for whom are translations done in India? The average monolingual reader? The academic bilingual reader? The colonial reader? The postcolonial reader? How does a translator create an audience?"(Ramakrishna, 2000, p. 98). Since the nineties, it is the middle class in India, who have promoted cultural productions exhibiting the nation-state's diversity. Ethnic writings which attempt to reflect upon their own diversity through varied representations emanating from the idea of a diverse India, is an example of cultural productions which were patronized by the middle-class. To borrow Partha Chatterjee's arguments regarding Colonial Calcutta, the rising middle-class and interest in questions of representation, was a product of a class of people being caught between the political and economic domination of the elite as well as their assumption of "cultural leadership of the indigenous colonized people"... "simultaneously placed in a position of subordination in one relation and a position of dominance in another" (Chatterjee, 1993, p. 36). This resulted in the production of literatures in English that were a product of "radical curricular and pedagogical shift" in comparison to the more inherited conservativism which characterized the post-independence pedagogy (Pillai, 2015, p. 150).

Therefore, the marginalized texts that were in translation did not just cater to the exoticist imaginations of a western reader, but to a rising middle-class in India who were actively promoting This Open Access article is published under a Creative Commons Attribution Non-Commercial 4.0 International License (http://creativecommons.org/licenses/by-nc/4.0/), which permits non-commercial re-use, distribution, and reproduction in any medium, provided the original work is properly cited. For citation use the DOI. For commercial re-use, please contact editor@rupkatha.com. 
the diversity of the Indian nation. It was their moral duty to take up the cultural leadership of India's rural, tribal, marginalized classes. While this phenomenon played a role within the intralingual publishing of vernacular literatures, it was the English translations which gave these texts, both a national as well as an international audience. It is within this socio-economical continuum which the translation of CK Janu's Janu: CK Januvinte Jeevithakadha came about.

\section{Literature Review}

The American translation theorist, Lawrence Venuti, in his seminal work, The Translator's Invisibility: A History of Translation had proposed foreignization as an effective strategy in resisting "ethnocentrism and racism, cultural narcissism and imperialism" (Venuti, 1998, p. 16). Foreignization refers to the minor disruptions made to the generic and linguistic patterns of the target language in order to situate the translation as an 'Othered' text, a text that is unique from an everyday text of the same language. These variations will help cultivate "a heterogeneous discourse, opening up the standard dialect and literary canons to what is foreign to themselves, to the substandard and marginal" (1998, p. 191). Venuti, therefore, takes up an ethical stand to prescribe foreignization as a desirable strategy to append the linguistic violence that a translation may entail.

This sentiment has been shared by regional translators and academicians who argue that since translation is not target-language oriented, it is important to resist any form of domestication. Translators "are representing a regional culture for a more powerful national or "Indian" one, and when this translation is made available to a readership outside India, we are also representing a national culture for a still more powerful international culture - which is today, in effect, a Western one" (Tharu \& Lalita, 1991, p. xx). The way to do so is by maintaining the regional flavour of the language using various strategies to achieve foreignization.

Critics such as Tymoczko criticize Venuti's distinction between foreignization and domestication, by arguing that it is not possible to define a translation by setting it within an orientation as either fully foreign or domestic, as the text can never be fully either. Venuti, according to Tymosczko, also fails to define or categorize these terms concretely so as to find patterns or clear methods (Tymoczko, 1998, pp. 55-56). While the ethical imperative behind Venuti and other translators hold ground, the lack of a concrete method to achieve this effect makes the process often tokenistic or exoticist. How much of a text needs to be foreignized in order to be considered free of domestication? This ambiguity makes Venuti's concept highly subjective. More importantly, foreignization can run the risk of being tokenistic in nature in order to serve a market that demands alterity in a time when alterity is celebrated. In this regard, Tarek Shamma argues that, in order for Venuti's adoption of foreignization and its aim "to challenge its readers' estimation of other peoples or, especially, of themselves" to work, "the two cultures and languages involved should be in a proper configuration of power relations" (Shamma, 2005, p. 64). Shamma, uses the example Richard Francis Burton's translation of Arabian Nights to showcase how the use of archaisms, or the use of untranslated Arabic words in the translation work to show how foreignization has the overall effect rather, of exoticizing. 
Therefore, it is argued here, that in the case of collaborative ethnic autobiographies, the translators and publishers often employ a strategy which can be explained by the coinage, 'strategic foreignization'. In many cases, publishing houses and/or translators, employ foreignization as a strategy to invoke an exotic appeal to the text. Arun Mukherjee, the translator of a Dalit autobiography written in Marathi titled Joothan, speaks of how the English translation published for an Indian audience had to be changed to suit the needs of the international market when it was taken up by an international publisher (Godard, Mukherjee, \& Mukherjee, 2006, p. 4). While it was originally translated, Joothan was given an additional subtitle, A Dalit's Life. However, while the text was brought out for an international audience, the subtitle was changed by the Press to 'An untouchable's life'. This was done due to the fear of reaching out to an audience which would "know enough about "untouchables" to be attracted to an "untouchable" writer's book. Certainly, two unknown, "foreign" words in the title would not have helped the sales" (2006, p. 4). However, the fact that the term 'untouchable' is dated and is now considered offensive by Dalits, shows how the market dictated translational choices supplants the politics which it selfevidently claims to support.

Some critics, such as Pramod Nayar and Rakesh Ramamoorthy, present the subject in subaltern autobiographies as one strategically enacting the various identities as a "knowing subaltern" (Nayar, 2014, p. 3; Ramamoorthy, 2019, p. 226). However, these arguments fail to take into account the complexities of mediation occurring within a collaborative ethnic autobiography. In the process of translation, a collaborative autobiography goes through an additional level of mediation, where the dominant language and its nuanced politics wield and exert undue powers upon the source text via the translators and publishers. PP Raveendran identifies translation as the fourth level of mediation occurring within CK Janu's collaborative autobiography, coming after "the autobiographer Janu, her former self that is the subject, and ubiquitous Bhaskaran" (Raveendran, 2007, p. 192). Furthermore, the translator further speaks of the textual mediations ("fine-tuning") made by Mini Krishnan, the editor and Ritu Menon, the publisher, along with Zacharia, a popular Malayalee writer (Shankar, Bhaskaran, \& Janu, 2004, p. xii). It is clarified that they had objected to the extreme linguistic experiments which the translator attempted, as they had "objected to distorting the language in this manner"(Shankar et al., 2004, pp. xi-xii). However, apart from certain changes made, the overall text was a product of the moulding undertaken by the experienced hand of Mini Krishnan and Ritu Menon, explicating the complex workings of a collaborative ethnic autobiography which is an aspect which is often glossed over by critics such as those mentioned above. It is in this background that this paper attempts to read the translation of CK Janu's autobiography as an exoticizing of subaltern life.

\section{Translating the Subaltern Voice}

The translator of Mother Forest employs several strategies to achieve this effect. It does so through the use of transliterated words written in italics, an act that has been described as "Orientalist and Anthropological" (Tharu \& Lalita, 1991, p. xxiv). It is a common practice in postcolonial translation to not translate certain vernacular terms to English and intersperse them within the English text in italics. This is done for two reasons. One, certain culturally loaded terms are deemed untranslatable as equivalent terms in English are not available to the translator. 
Secondly, it is a tool used by the translator so that the text can exoticized. In any case, the use of italics can work to increase the distance between the text and the assumed reader. As early as 1940, Indian writers had noticed the tendency of international publishers to italicize vernacular terms used in their writings. In the post-colonial period, postcolonial writers such as Rushdie is said to have perfected the used of hybridisation or 'chutnification', where they use vernacular words within English texts with descriptions of the same term is added within the text or through the use of glossaries. The unequal power equations between two languages and contexts make the need to explain things to the reader seem natural. Thus, as Vikram Seth says, "there are no glossaries for Faulkner and Dickens" (as cited in Ranasinha, 2013, p. 29), while ethnic texts are adorned with glossaries and explanations in a truly Orientalist fashion.

The strategy is to foreignize the text in order to make a text appear 'exotic' for an outsiderreader, while not so much as to make it unapproachable to the same person. While Mother Forest can superficially be read as a text which foreignizes English so as to challenge the impositions of a dominant target language, a detailed reading of the text unravels the text as one which engages in what can be deemed 'strategic foreignizing'.

In the text divided into two chapters, the first chapter which details the pre-political childhood of CK Janu is sprinkled with such terms particularly in the context of cuisine. If caste names, which are proper nouns without translations, are excluded, more than half of the source language words retained in English were related to food items used by the Adivasis. While these retentions are intended to retain the "flow of the language" (Shankar et al., 2004, p. xii) according to the translator, they may be read as instances where the translator has employed strategic foreignization, which serves to present the text as an exotic narrative.

This is evident even in cases when certain words are chosen to be retained without translating, while some others are not. For example, while the fish such as Paral (Puntius mahecola) or Mussu (Clarias batrachus) are italicized, waterfowls, a generic term for various aquatic birds are substituted in the case of Kundakozhi (Janu \& Bhaskaran, 2003, p. 12; Shankar et al., 2004, p. 2). It becomes clear that such retentions are clearly a subjective and arbitrary choice made by the translator, and not based on any steadfast rule on what is to be kept as original and what is not.

The case is further clear when certain English terms such as "cinima" [sic] (Shankar et al., 2004 , p. 51) are chosen to be transliterated rather than be translated along with the sentence. The term has no significance in the Adivasi culture, in order for the term to be 'preserved' in English, other than to merely showcase the distinct manner in which Janu pronounces the word. In fact, the word is of common use in the Malayalam language itself, following the standard British pronunciation of the term (IPA: /'sIn.I.ma:/). This usage has no cultural significance or referential power in Adivasi language practices. Orthographically or phonetically too, the usage does not have any purpose within the text. In fact, the glossary of the text merely defines the usage as "the popular word for cinema" (2004, p. 68). Therefore, it is clear that certain italicized terms such as cinima, payar (beans), or thuvara (pigeon peas) are not culturally significant or used to represent the unique flow of Janu's language or the linguistic features of any Adivasi community, but merely as tools for exoticized representation of the Adivasi.

Another translatorial practice, which tends to undercut the foreignization strategy, is the way in which the text explains terms or practices that are unknown to the prospective reader 
within the translated text. Such explications are helpful in aiding an outsider-reader to ease into the text. It, however, goes against the standard of foreignization of the self-professed need to reflect Janu's intonation. This tendency may be read as the text's intent to serve a dominant international reader base, while strategically engaging with foreignization through italicized terms, that are explicated using a glossary. The need is to make a unique text more accessible to the international and national literary marketplaces, that is at once exotic and accessible. "In postcolonial writing, the amount of cultural material that is explained explicitly serves as a kind of index of the intended audience, with greater amounts of explicit material indicating that a text is aimed at the former colonisers and/or a dominant international audience" (Tymoczko, 2012, p. 29).

For example, in the first chapter, Janu explains how the bushes are burnt to clear land, in a process called punam. In the original, though the concept is explained, it is never linked to its name. It is merely said that "Punam is burnt so"(Janu \& Bhaskaran, 2003, p. 11). However, in English, the translation adds "we call it torching the punam" (Shankar et al., 2004, p. 1). Similar explanations are added to accommodate the foreign reader to the text. In the next paragraphs, while describing the process of catching fish or trapping waterfowls, additional descriptions are added to the text $(2004$, p. 2). Descriptors such as "thickets of kaitha growing abundantly by the stream" and "tiny fish like paral and mussu", were additions made to the original narrative as a way to describe indigenous life to a foreign reader. This form of additions to the text, in original and in translation, is perhaps what prompts Meena T Pillai to argue that the entire first chapter which describes Adivasi life in an ethnographic manner cannot be identified as the true voice of C.K. Janu:

However, it is interesting to note that the world view, which is almost a bird's eye view of the adivasi life that Janu seems to present in the first chapter can hardly be the result of her own conscious contemplation and speculation but a process nudged and prompted by the ethnographer and translator in order to construct a particular kind of discourse of the subaltern, that is then condensed. formatted, published and reviewed as a postcolonial text that 'centers' the margins. (Pillai, 2011, p. 18).

\section{Premodern Past versus the Politically Modern Present}

The text's two-part structure assumes a transformation from or 'unadulterated' childhood memories of the subject set in a pristine past towards a rather modern political life. The first chapter employs the metaphor of an all-providing Mother Forest which "had turned into the Departmental Forest" (Shankar et al., 2004, p. 30) in the second chapter. This extrapolation of a Goddess/Mother-figure in these lines by the translator is done despite the claim made that the only compromise that he had to make with great reluctance was the use of precise personal pronouns for clarity (2004, p. xi). The notion of a forest that protects the Adivasi like a mother and it being taken away by the colonial/national governmental structures, presents a neat dichotomy between a glorious past and the difficult present. In the pre-modern Adivasi past, the Adivasi was one with nature, provided for and nurtured by nature. Modernity as the enemy of 
tribals is a common trope employed by translators and collaborators in ethnic autobiographies, such as that of Mayilamma and Janu.

The usage, 'Mother Forest', which became the title of the translation, is in fact never found in the Malayalam original. In the English text, it is found being used at the beginning of the second chapter. However, in the Malayalam text, it merely mentions, "[o]ur people had become mere wage-labourers. All Jungles had become Forests" (Janu \& Bhaskaran, 2003, p. 28). Instead, Ravi Shankar translates it as: "Our people had turned into mere wage labourers. Mother Forest had turned into the Departmental Forest" (Shankar et al., 2004, p. 30).

However, this romantic glorification of the Adivasi past within the text fails to hold ground while Janu reminisces the realities faced at a non-metaphorical level. While portraying Adivasi life as one without ever knowing hunger $(2004$, p. 2) and without worries about hunger in the first chapter, we continue to see the inherent injustices meted out to Adivasis by wealthy landlords of the region. The Adivasis are forced to rely upon whatever is available to them, as the harsh and long working hours under landlords would be that "it would be quite dark by the time we reached our hovels... we would be hungry and cold... we wouldn't be able to see each other since we had no lights. Any way everyone must look the same when hungry" (2004, p. 14).

However, there are instances within the text where the subject's speech contradicts the structure of the book and therefore, Janu speaks of the hardships that the Adivasis had to endure in the past, undercutting the image created by the translator and collaborator. There are portions within the narrative which contradict the image of this perfect past represented in the title as well as the text. In the first chapter, one can find Janu describing the forest as a nurturing figure where no hunger was ever felt and her childhood is described in detail as pristine descriptions which match the tone set for the first chapter by the collaborator. However, within the same chapter, Janu talks about how the Adivasis were exploited by the landlords who kept them working long hours with very little time to eat or rest. Children would fall asleep without being able to eat food at such late hours.

when we worked in the rainy season we could leave only after planting the whole field. it would be quite dark by the time we reached our hovels. even after reaching them, we would not be able to sleep immediately. we would be so hungry and cold. it was impossible to kindle the fire in the hearth. we would eat some chakka or thina. the little ones would sleep even without that. (2004, p. 14).

Similarly, in the second chapter, Janu talks about how the Adivasis were dispossessed by the landlords or others who would then employ them to work in lands that were their own:

Our people have always used the land around our huts for sowing thina, thuvara or ellu. When our ancestors cleared the woods, burnt the undergrowth, sowed thina and converted the earth into fields, the jenmi and the migrants of that time would make an appearance. They would befriend our men, give them arrack or a small sum of money and transfer the land in their names. Our people, who had never had to keep records and documents for their lands, would once again have to work in those same lands as labourers and grow crops for the jenmi. (2004, pp. 31-32) 
Even while addressing the forest as an all provider, hunger is a pervading emotion expressed in Janu's narration of the past, undercutting the presentation of her 'Mother Forest'. Janu identifies hunger to be a collective experience of the tribal community. It pervades and overrides all emotions.

Meena T Pillai observes that the language of the text cannot be assumed to be a free speech and terms it to be "a process nudged and prompted by the ethnographer and translator in order to construct a particular kind of discourse of the subaltern, that is then condensed, formatted, published and reviewed as a postcolonial text that 'centers' the margin" (Pillai, 2011, p. 18). She further argues that the language of translation is, in fact, an elitist academic game, where the intonations and patterns of CK Janu's speech are judged primitive. "So what Bhaskaran and Ravi Shankar together do is an act of 'cultural translation' where the language of the translation does not merely posit the notion of an English vs. a tribal Malayalam but a hegemonic, culturally elitist, academic 'play' vs. a certain mode of life that judged by the former standards would translate as primitive and uncivilized" (2011, p. 18).

Ravi Shankar speaks of his desire to "retain the flavour of Janu's intonation and the singsong nature of her speech in translation" (Shankar et al., 2004, p. xii). However, in a personal interview, he speaks of how the original collaborator had "created a language of first-person speech as an Adivasi would speak it in Malayalam. It is not Janu's speech. The creative effort is of Bhaskaran" (Shankar). The translation is thus, an exoticist imitation of the original exoticist rendering of Adivasi voice in Malayalam. The translator mimics the "creative effort" of the original collaborator (Shankar, 2021) by using a jarring reversion of modern English diction to an exoticist imitation, which narrowly resembles Old English.

He quotes his own early version as:

Where we all lived there was time when work meant pullinge out the paddy seedlings, transplantinge them in the fields and such/ mostly work related to/ paddy faarminge/ plantation work became common much later/ work like manuringe coffee manuringe pepper aand such were simply not there/ most of the toilinge we did only in the rice fields/ carrying dung to the fields digginge up the soil with spades sowinge pullinge out of the seedling transplantinge them weedinge wateringe reapinge carryinge the sheaves of corn aand such. (Shankar et al., 2004, p. xi)

This particular style was to be adopted by the translator as an effort to aptly translate local speech rhythms, idioms and cultural specificities of Janu's speech. In doing so, the translator "used the simplest language possible, keeping the flow of the language close to the Malayalam that rolled off Janu's tongue" (2004, p. xii). However, this style did not make it into the final version. The translator says, "some friends asked me not to do it. I relented..." (Shankar, 2021). However, other forms of linguistic experiments persisted in the text, as discussed before, particularly with regard to letter cases and the general fragmentary nature of sentences. In addition to this, the translator employed capital letters in the case of certain nouns while referring to elements of modern life within the text, to signify how Adivasi life and culture existed outside it. "What I meant 
was that anything exterior to Adivasi life should bear a capital letter. Because they were new things entering their life" (Shankar, 2021).

\section{Conclusion}

The problem lies with the need, assumed by the translator or the editors, to retain the intonations of one's language in its written form, especially in an unphonetic language such as English. By excluding the Adivasi culture as one existing outside the normal progress of human cultures, these experiments echo the popular imagining of the Adivasi as the savage. The burden to keep "the flow of the language" (Shankar et al., 2004, p. xii) is seldom placed on autobiographies written by those belonging to dominant/mainstream cultures. However, the need to exoticize or 'primitivize' Janu's language and to set it apart in an English translation, weighs upon the translator's desire to experiment with the language. This is one of the primary ways in which the translator presents before his English readers, an exoticized language and diction from the 'subaltern who speaks'.

This is not to claim however that Indian writers, though mostly of fiction, previously have not employed varied narrative standards to express speech effects and variations of regional accents and standards of English. However, to use it for a particular effect in the autobiographical speech of a marginalized writer to achieve the tone of ethnic simplicity marked by an egregious language style, is problematic. The need to transpose the 'irregularities' of Janu's Malayalam into English results in creating a language that is "strange and inexplicable", a complaint raised often in the case of Indian English writers who use quaint expressions and " strange adjectives when legitimate English attributes could have served well" (Mukherjee, 1971, p. 180). Standard English cannot reiterate Janu's Otherness and exoticity, the way this unique parole can. The resultant text makes the process of reading as foreign and as quaint as possible.

\section{Funding Disclosure/Acknowledgement}

I declare that this work has received no funding from any agency or institution.

\section{References}

Chatterjee, P. (1993). The Nationalist Elite. In The Nation and its Fragments: Colonial and Postcolonial Histories (First). Princeton: Princeton University Press.

Godard, B. J., Mukherjee, A. P., \& Mukherjee, A. (2006). Translating Minoritized Cultures: Issues of Caste, Class and Gender. Postcolonial Text, 2(3), 1-23. Retrieved from https://www.postcolonial.org/index.php/pct/article/view/501

Janu, C., \& Bhaskaran. (2003). Janu: CK Januvinte Jeevithakadha (1st ed.). Kottayam: DC Books.

Mukherjee, M. (1971). The twice born fiction: Themes and techniques of the Indian novel in English. New Delhi: Arnold-Heinemann.

Nayar, P. K. (2014). Indigenous cultures and the ecology of protest: moral economy and "knowing subalternity" in Dalit and Tribal writing from India. Journal of Postcolonial Writing, 50(3), 291-303. https://doi.org/10.1080/17449855.2013.815127 
9 Translation as Strategic Foreignization: A Study of the Politics of Translation in Mother Forest: An Unfinished Autobiography

Pillai, M. T. (2011). The English-Speaking Gendered Subaltern: Sales Tags for Postcolonial. The Journal of the School of Language, Literature \& Culture Studies, 15(2).

Pillai, M. T. (2015). Cultural Studies and the Reinvention of English Pedagogy in India. Ariel, 46(1-2), 143173. https://doi.org/10.1353/ari.2015.0006

Ramakrishna, S. (2000). Cultural Transmission Through Translation: An Indian Perspective. In S. Simon \& P. St-Pierre (Eds.), Changing the Terms: Translating in the Postcolonial Era. Ottawa: University of Ottawa Press.

Ramamoorthy, R. (2019). Modernity at Arm's Length: Strategic Exoticism in Mother Forest: The Unfinished Story of CK Janu. Literary Endeavour, X(2), 226-230. Retrieved from https://www.literaryendeavour.org/files/rvmbywrvbpmn8sgniyvz/2019-04 51. Modernity at Arm\%27s Length Strategic Exoticism in Mother ForestThe Unfinished Story of C. K. Janu- Rakesh Ramamoorthy.pdf

Ranasinha, R. (2013). Writing and reading Sri Lanka: Shifting politics of cultural translation, consumption, and the implied reader. The Journal of Commonwealth Literature, 48(1), 27-39. https://doi.org/10.1177/0021989412470951

Raveendran, P. P. (2007). Translation as Hoax: Art, Othering and Life Writing. Indian Literature, $51(1$ (237)), 187-201. Retrieved from http://www.jstor.org/stable/23347895

Shamma, T. (2005). The Exotic Dimension of Foreignizing Strategies. The Translator, 11(1), 51-67. https://doi.org/10.1080/13556509.2005.10799189

Shankar, N. R. (2021). Email Interview. Conducted by Liju Jacob Kuriakose.

Shankar, N. R., Bhaskaran, \& Janu, C. (2004). Mother Forest: The unfinished story of CK Janu (1st ed.). New Delhi: Kali For Women \& Women Unlimited.

Tharu, S. J., \& Lalita, K. (1991). Women Writing in India: 600 B.C. to the early twentieth century. Feminist Press at the City University of New York.

Tymoczko, M. (1998). Translation in a Postcolonial Context: Early Irish Literature in English (1st ed.). London and New York: Routledge.

Tymoczko, M. (2012). Post-colonial Writing and Literary Translation. In S. Bassnett \& H. Trivedi (Eds.), Postcolonial Translation: Theory and Practice (pp. 19-40). United Kingdom: Taylor \& Francis.

Venuti, L. (1998). The Scandals of Translation: Towards an Ethics of Difference. London and New York: Routledge.

Dr. Liju Jacob Kuriakose, having completed his PhD from the National Institute of Technology Puducherry, is presently an Assistant Professor in the Department of Language and Literature at Alliance University, Bangalore. He has published several translations in English and Malayalam with ongoing projects for national and international publishers. His areas of interest include translation studies and postcolonial studies. He is presently working on autobiographical writings of contemporary Dalit-Adivasi leaders from Kerala. 